Article

\title{
Analysis of the Visual Perception of the Competences of Project Managers
}

\author{
Rocio Poveda-Bautista ${ }^{1}\left(\mathbb{D}\right.$, Jose-Antonio Diego-Mas ${ }^{2, *(\mathbb{D})}$ and Jorge Alcaide-Marzal ${ }^{2}$ \\ 1 INGENIO (CSIC-UPV), Institute of Innovation and Knowledge Management, Universitat Politècnica de \\ València, 46020 Valencia, Spain; ropobau@upvnet.upv.es \\ 2 i3B, Institute for Research and Innovation in Bioengineering, Universitat Politècnica de València, \\ 46020 Valencia, Spain; jalcaide@dpi.upv.es \\ * Correspondence: jodiemas@dpi.upv.es
}

Citation: Poveda-Bautista, R.;

Diego-Mas, J.-A.; Alcaide-Marzal, J.

Analysis of the Visual Perception of

the Competences of Project Managers.

Sustainability 2021, 13, 4984

https://doi.org/10.3390/su13094984

Academic Editor: Maria Socorro

Garcia Cascales and Francisco

Ortega-Fernandez

Received: 30 March 2021

Accepted: 26 April 2021

Published: 29 April 2021

Publisher's Note: MDPI stays neutral with regard to jurisdictional claims in published maps and institutional affiliations.

Abstract: Based on the appearance of their faces, we attribute to people personality traits, moods, capacities, or competences. This unconscious process plays a central role in our everyday decisions and how we choose partners or our favorite candidate. This work is the first approach to the analysis of the influence of appearance-driven judgments of faces in the project management field. The main objective of this study was to obtain an approximate image of the general mental prototype of the face of a project manager using noise-based reverse correlation. The obtained image shows the features of the faces that drive the perception of a good project manager. The face shows very high average scores for all the competences recognized in the IPMA Individual Competence Baseline when assessed by a sample of project management practitioners. From these results, it can be stated that people have clearly defined prototypes of facial features that convey the perception of being a competent project manager, and this finding may have implications in the project management field.

Keywords: project management; face perception; competences

\section{Introduction}

We have neural networks in our brain specialized in processing face information [1,2]. Face perception research has found that human beings are able to quickly detect and identify faces [3,4], and through the information gathered from them, determine the gender, the race, and guess the age of people. But our behavioral capacity for facial perception goes further. We are capable of extracting a lot of information from facial features. We can estimate the aims and intentions of people that interact with us or detect the emotional state of our interlocutors. Based on the appearance of their faces we attribute to people characteristics, such as intelligence, dominance, or honesty [5-7]. It is a common belief that the face is the most direct way to know the true nature of a person; a window showing their feelings and emotions [8]. Now, recent studies have shown that our brains need only 34 milliseconds of exposure to recognize a face and to form an impression of the owner's personality traits or moods [9]. And longer exposures do not change these first impressions.

Personality traits, moods, capacities, or competences are not directly observable on a face; they are inferred by our cognitive system [10]. The visual input is matched to mental templates or representations of what we are trying to judge [11,12]. For example, when we see someone for the first time, we judge if that person is trustworthy by comparing their face to our mental prototype of the face of a trustworthy person. Although this process is fast and unconscious, and it has more to do with perception than with thinking [13], it plays a central role in our relationships [14] and everyday decisions $[15,16]$. When we meet someone, we immediately judge and interpret their personality traits, moods, capacities, and competences from the appearance of the face, and our relationship with that person is conditioned, in some way, by these judgments. For example, several studies have found that the appearance of the face greatly influences how we choose social partners [17], 
mates [18-20], our favorite candidate in an election [16,21], or how the members of a jury make a decision [22].

Psychological research has studied this issue for a long time but, now, because of the great influence on our lives of the judgments driven by the appearance of the faces, this topic has attracted the attention of researchers from other fields, such as engineering, marketing, software development, human resources management or teamwork, and group dynamics research [23]. Leadership selection and compensation is one of the most studied domains [9]. For example, several studies have shown that CEOs' appearance predicts company profits [24] and that CEOs with competent and dominant-looking faces receive larger salaries and are hired by more important companies independently of their performance in respect to other peers [25]. This is true only for Caucasian male CEOs because the success of black male CEOs is positively predicted by baby-faceness [26].

Therefore, appearance has been shown to play a key role in some professional fields, affecting peer relationships, performance, selection procedures, and compensation. This is due to an unconscious matching process between the face of the people and some kind of mental representation of what we are trying to judge [11,12]. From the mere appearance of a face, the observer can only infer moods, simple emotions, and attitudes [5-7]. But, if these mental images exist, we can make more intricate judgments, like the competence to perform some complex tasks. These mental prototypes have been found for CEOs, bankers, athletes, businessmen, nurses, or doctors [25-29]. Therefore, when we see a face for the first time, we infer the capacity of that person to be a good businessman matching the visual input to our mental prototype of the face of a businessman.

This work is the first approach to the analysis of the influence of appearance-driven judgments of faces in the project management field. Has the appearance of project managers (PMs) an effect similar to those in other professional fields? For this to happen a mental prototype of the face of a PM must exist. PMs must have several specific competences [30-34]. They should be trustworthy, good leaders and communicators, skilled in motivation tactics, able to respond to uncertainty, or manage conflicts [35]. Therefore, our research question is: does a prototypical face of a PM exist?

To answer this question, the first step of this work is to obtain an approximate image of that general mental prototype of the face of a PM. Mental prototypes are different for each observer, therefore we are looking for a consensual visual prototype [27], something like the average prototypical face of a PM, which we will hereafter call prototypical face (PF). Obtaining the PF is a complex task that implies visualizing a mental representation. To do that, we used a noise-based reverse correlation (NBRC) procedure [10], a psychophysical reverse correlation technique [36] that provides images of the content of the mental representations of faces.

Once this mental prototype is obtained it is necessary to confirm that elicits the expected competences in the observers. Namely, if the PF is perceived as the face of a person with the main personal competences that a PM must possess. Therefore, in the second step of this work, we measure if the obtained mental prototype of a PM is aligned with the expected profile. In the next section, we review the competences recognized by the majority of project management standards and authors as the main competences for an effective PM, and we select those appropriated to be considered in this study. Then, we briefly show how the noise-based reverse correlation method can be used to obtain a PF.

\section{The Project Manager Competences}

One of the main causes of project failures is recruiting an unsuitable project manager. The concept of competence is necessary to find out how project managers' skills fit the objectives of the project [27]. Müller and Turner [28] argue that managerial competences are often meaningful, although emotional competences always make a significant contribution to project success. Besides, and according to El-Sabaa [29], human skills have a greater influence on project success than technical skills. Therefore, being an effective project manager implies having the core personality competences [30]. According to the World Economic 
Forum (WEF) [31], the expectation is that, in the coming years, there will be a substantial change in the core skills valued in the labor market. WEF recognizes interpersonal skills as one of the essential competences to manage a business successfully [32].

Measuring the development of the competences of PMs in their workplaces requires recognized reference standards. In other words, the demonstrable performance of project management competences must be endorsed by competence-based standards. Nowadays, most of the standards focus on processes and procedures (e.g., MSP by Axelos, PRINCE2, P2M, and PMBoK by PMI). However, fewer standards are competence-based and stipulate the competences that people need for a good performance in the project management field (e.g., ICB, APMBok, and PMCD [33,34]).

Competence-based standards define personal characteristics, skills, abilities, and knowledge needed to optimize performance. Standards, such as ICB and APMBoK, identify the personal characteristics of an effective project manager within their competences. However, in general, most of the standards have paid more attention to the required knowledge than the personal characteristics of the PM [35]. These personal characteristics are difficult to assess due to their intrinsic subjectivity, and, according to some authors [36], most of the PMs selection procedures are based on a subjective assessment of the candidates. Therefore, the assessment processes could be unconsciously conditioned by the appearance of the candidates.

As it has been pointed out in the previous section, this kind of judgment is made by the evaluator matching his/her own PF of a PM and the face of the evaluated candidate. The main objective of this work is to materialize this PF. Namely to visualize through a real image the common mental prototype of a face that fits the competences of a PM. Given the influence that this PF has on the visual perception of the competences, our second objective is to contrast if the face in the resultant image effectively conveys to the observer those personal competences defined in the competence-based standards.

In this study, we used the ICB4 competences of IPMA Individual Competence Baseline v.4 [37] as a reference. ICB4 divides the competences into three areas: People, Practice, and Perspective. This standard is focused on the personal development of the people involved in the project management field. It is not oriented to the projects or the organizations like the rest of the standards, but it does on the individuals. In this work we analyze personal competences, looking for those that can be perceived in the PF of PMs. Since ICB4 is focused on the persons, we chose this standard as a reference to select the competences to be studied. Specifically, we analyzed the competences of the People competence area of ICB4 performing a literature review identifying personal competences recognized by a wide number of authors and their correspondence with ICB4 competences.

Table 1 summarizes the personal competences considered as required for the PM job by several authors. All competences found were already included in the ICB4 standard. After that, these competences were grouped and related to those of the ICB4 People competence area. From this literature review, we selected for our study 7 competences of the People competence area of ICB4: Leadership; Personal Communication; Negotiation, Conflicts, and crisis resolution; Relationships and engagement; Resourcefulness; Teamwork and Personal integrity and reliability. 
Table 1. Personal competences of the PM and correspondence in the People competence area of ICB4.

\begin{tabular}{cc}
\hline Competences [References] & Corresponding ICB4 Competence \\
\hline Leadership [35,38-40] & Leadership \\
\hline Communication [35,36,38,39,41] & Personal Communication \\
\hline Reliability [42] & Personal integrity and reliability \\
Personal Integrity [42] & Negotiation, Conflicts and Crisis Resolution \\
\hline Conflicts Resolution [43] & \\
Negotiation Skills [41] & \\
Empathy [38] & \\
Commitment [44] & \\
Personal relationships [39] & \\
Motivation [45] & \\
Optimism [40,46] & Resourcefulness \\
Resourcefulness [45] & \\
Creativity [36] & \\
Problem resolution [47] & Teamwork \\
Teamwork [48] & \\
Diversity awareness [49] & \\
Cultural awareness [35] & \\
\hline
\end{tabular}

\section{Reverse Correlation Methods for Face Perception}

Despite the logical dispersion of the opinions, faces convey similar impressions to everybody [14] and, to some extent, it is possible to model this relationship. The simplest and most direct approach to get these models of the stimulus-response relationships is by modifying the stimuli in a controlled way and correlating the features of these altered stimuli with their corresponding responses. Using this conventional direct approach is possible if we are interested in relating a few specific features of faces to some social judgment. However, this approach is less feasible when the stimulus is the global appearance of a face. Faces are perceived holistically [50]. This means that we process the whole information from the face simultaneously, and we don't treat each facial feature in an independent perceptual process. In this case, using a direct approach is not feasible because the number of facial features that drive the social perceptions is, practically speaking, infinite, and it is not possible to summarize the global appearance of a face through a few variables.

Reverse correlation (RC) methods [51,52] are more suitable to relate global facial appearance to social judgments. RC acts in the inverse way that direct methods do. Using direct methods supposes to fix a set of relevant attributes of the face, which are supposed to drive the perception, and vary their values to find the correlation to the responses. On the contrary, RC methods don't need to establish the features of the stimuli that drive the judgment. The stimuli are random variations of faces that are subsequently classified regarding the social judgment depending on the responses given by the respondents. Correlating the randomly modified stimuli and their responses it is possible to identify which variations in stimulus attributes caused the response pattern. This data-driven procedure does not require assumptions about the attributes of the faces that drive the judgment $[10,52]$ and the respondents are free to employ their criteria to assess the faces. The correlation between the responses and the random differences between the stimuli will determine the facial features that drive the responses.

\section{Noise Based Reverse Correlation}

A typical RC task involves generating stimuli randomly varying a base image, showing the stimuli to the participants, asking them about the target judgment. This basic procedure can be implemented in different ways [53]. NBRC is an implementation of the RC approach particularly adequate for visualizing mental representations [10]. The outcomes of these methods are psychologically meaningful images (so-called classification 
images (CIs)) that represent the PF that the participants used to match the social perception evaluated [10]. NBRC procedures have been extensively used in recent years to model emotional expressions of faces [54], to identify cultural differences in the perception of emotional expressions [55], to represent the face of stigmatized ethnic groups [56], to evaluate how immigrants are perceived [57], to obtain the CIs of some personality traits like dominance or trustworthiness [52], or even, to determine the PF of God [58]. As regards visualizing prototypical images for various professions, it has been used for bankers, athletes, businessmen, nurses, or doctors $[59,60]$. In this work, NBRC was used to obtain the PF of a PM.

In a typical NBRC implementation, randomly varied images of faces are created overlaying different random noise patterns over a base face. The base face should be specially fitted to the analyzed social judgment and the target population. Depending on the objective of the research, the base face could be masculine, feminine, or genderneutral, or could express some particular emotion. Typically, the base face is obtained averaging grayscale images from a face images database, which leads to base faces with blurry contours while the center of the faces remains well defined.

Variations of the base face are obtained superimposing random noise over the image of the base face. Three types of noise are commonly used: white noise, sinusoidal noise [52,54], or Gabor noise [61]. White noise patterns are generated giving each pixel a random grey value without constraints, while sinusoidal and Gabor noise patterns are generated superimposing sine-wave and Gabor patches.

In each trial of the RC task, two different versions of the base face are presented simultaneously side by side to the participants (other variants present four images at once) (Brinkman et al., 2017). One image is generated superimposing the random noise over the base face. To generate the other one, the noise pattern used to obtain the first image is inverted and applied over the base face again. Participants are asked to choose the version that best fits the target judgment and the process is repeated with two new random opposite versions of the base face. Typically, participants complete between 300 and 1000 trials. Finally, the noise patterns of the images that have been selected are averaged to obtain the $\mathrm{CI}$. The $\mathrm{CI}$ is superimposed over the base face, obtaining a final image that shows the features of the face that have driven the social judgment. Therefore, this image is considered an estimation of the participants' mental representation of a face that fits the target social judgment. The CI can be computed for every single participant as well as for all of them. Following the same procedure, superimposing the noise patterns of the images that have not been selected, an Anti-classification Image (anti-CI) is obtained. The anti-CI image shows the features of the face that do not drive the social judgment. An anti-CI likely visualizes the inverse of the prototypical face [51].

\section{Materials and Methods}

The experimental stage of this work was developed in two phases (Figure 1). In the first one, we selected a group of professionals in the project management field and performed a noise-based reverse correlation task. The objective of this stage was to obtain an image of the participants' mental representation of a face that fits the face of a PM. This image is an estimation of the features of the face that drove the judgment (the appearance of being a PM). In the second phase, the PF and the anti-PF previously obtained were evaluated by an independent sample of project managers to measure to what extent both images elicited each personal competence studied in this work. The objective of this stage was to check if it is possible to perceive the competences of a PM in the PF, and if there are significant differences between the perception of the competences in the PF and the anti-PF. 


\section{Phase 1}

Participants

cros
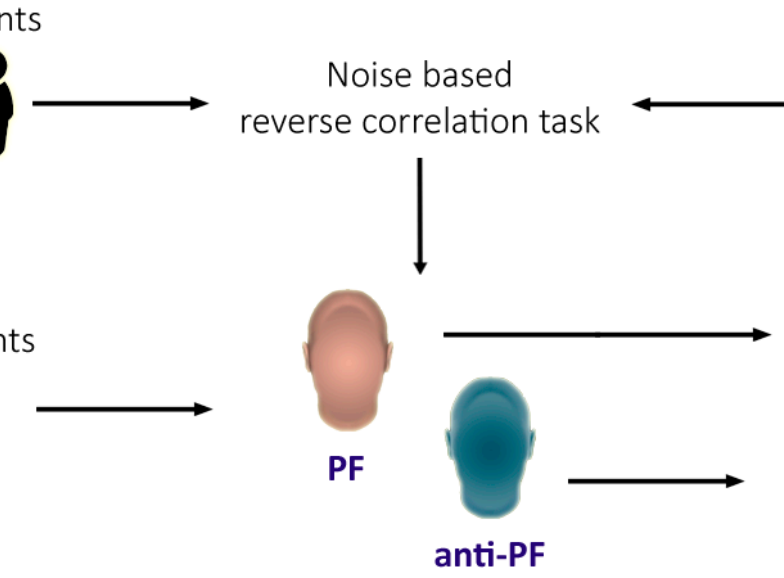

Judgment

Phase 2

Participants

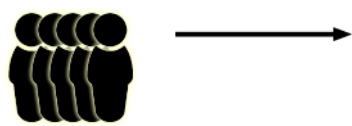

anti-PF

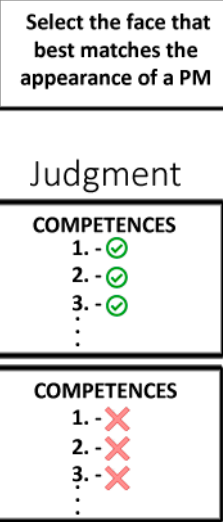

Figure 1. Experimental procedure: (Phase 1) noise-based reverse correlation task to obtain the PF and the anti-PF; (Phase 2) measurement of the perception of the competences in both faces.

\subsection{NBRC Task}

\subsubsection{Stimuli and Participants}

To obtain the stimuli, we used the base face created in Jackson et al. [58] with the kind permission of the authors. This base face was the result of averaging 50 representative faces of the US population including different genders, ages, and races. We generated 300 images (512 $\times 512$ pixels) of patterns of sinusoidal noise using the rcicr R package [62]. A complete description of the sinusoidal noise generation process is available in [52,54].

Each noise pattern was inverted, finally obtaining a set composed of 300 pairs of noise patterns (the initial pattern and the inverted one). Finally, every noise pattern was superimposed on the base face image, producing 300 pairs of different noisy versions of the base face (Figure 2). In each pair, one image is obtained using a noise pattern and the other one using the corresponding inverted pattern.

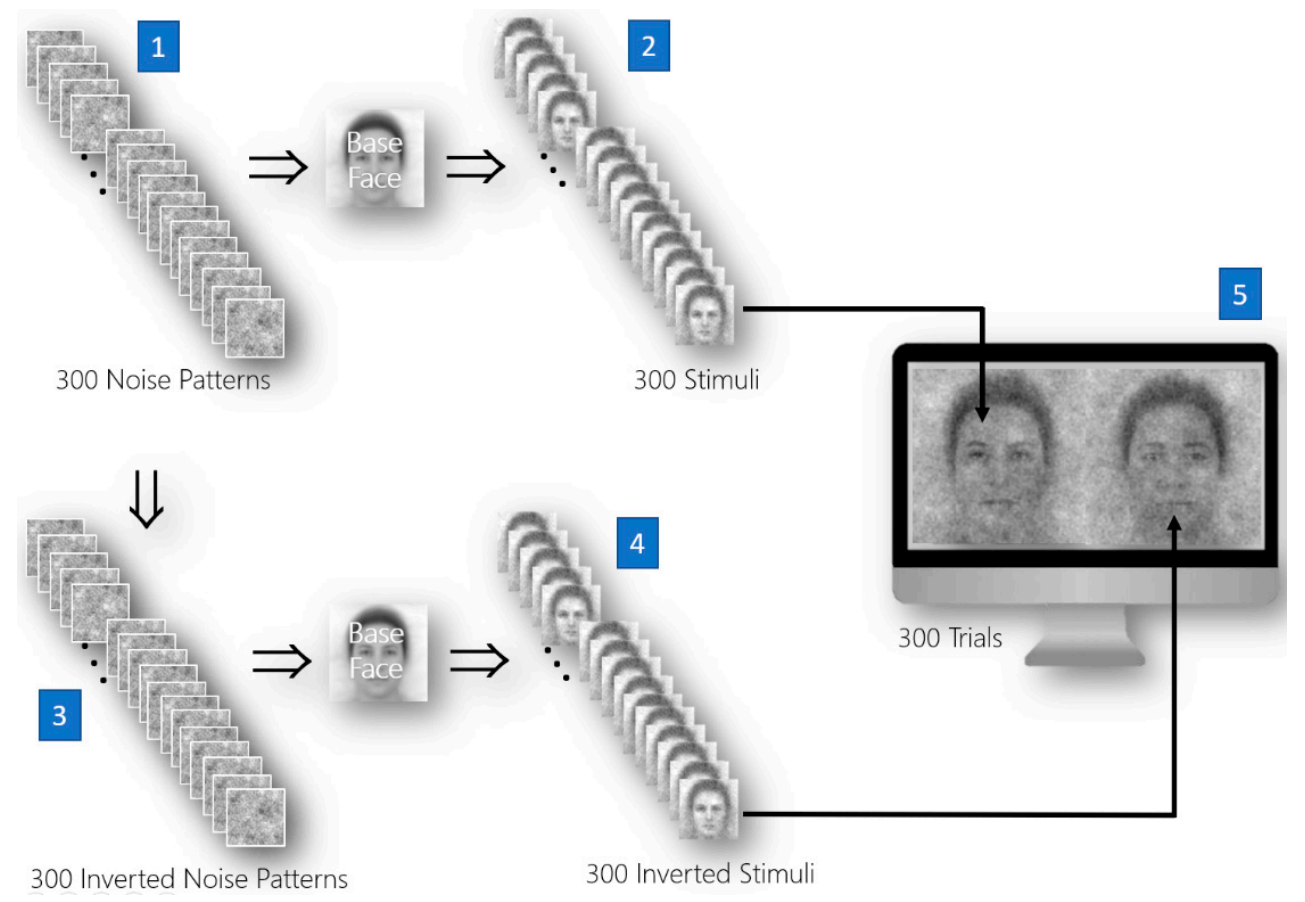

Figure 2. NBRC procedure: (1) noise patterns generation; (2) stimuli generation; (3) inverse noise patterns; (4) inverted stimuli generation; (5) stimuli presentation. 
A total of 32 Spanish and South American professionals of the project management field (16 men and 16 women) with ages varying between 24 and 57 years $(\mathrm{M}=31.00$, $\mathrm{SD}=9.94)$ were recruited to take part in the NBRC task. Participants were selected from among members of AEIPRO (Asociación Española de Ingeniería de Proyectos), which is the Spanish partner of the International Project Management Association. To cover the entire age spectrum, the sample was obtained through a systematic sampling of a list of members of AEIPRO ordered by age. All participants were involved in project management teams and provided informed consent to participate. The study was approved by the ethics committee at the Universitat Politècnica de València (P15_10_01_20).

\subsubsection{Procedure}

Participants completed 300 trials divided into two blocks of 150 trials, each one presenting one stimuli pair (the direct and the inverted one). The stimuli pairs were displayed side-by-side using a $1920 \times 1080$ resolution screen in random order and the position of the direct and inverted stimuli on the screen was randomized in each trial. All participants performed the task in the same controlled environment using the same hardware. Before the survey, participants were given a brief explanation of the procedure, asking them to select the face that best matched the appearance of a PM out of both presented in each trial. They were warned of the difficulty of the task and were asked to respond quickly, guided by their first impression.

Stimuli pairs were presented in random order without replacement to each participant, and the position of the direct and inverted stimuli on the screen was randomized in each trial.

\subsubsection{Data Processing}

9600 answers were collected (300 per participant). The average response time by trial across all participants was $3.67 \mathrm{~s}$. Data were processed using the rcicr (version 0.3.4.1) $\mathrm{R}$ package [62]. The individual Cis (the classification images of every single respondent) were computed averaging the noise patterns of the selected stimuli by one participant. In the same way, the noise patterns of the unselected stimuli were averaged, thus obtaining the anti-CI (anti-classification image) by subject. The CI and the anti-CI in an NBRC task are representatives of the extremes on a bipolar scale [51]. Therefore, in this study, the CI represents the PF of a PM, while the anti-CI shows what the respondent thought a non-prototypical PM face. Finally, the average PF for all the participants were generated by averaging the noise pattern of the individual CIs and overlaying the resultant pattern on the base image. In the same way, the anti-PF was obtained using the average of the noise patterns of the individual anti-Cis.

\subsection{Evaluation of the Visual Perception of the PM Competences}

The main objective of this phase was to analyze whether the PF obtained in the previous phase of the study elicited in the observers the expected personal competences of a PM according to those recognized by the ICB4. For this, a two-part survey was conducted. The first part was related to the PF and the second part to the anti-PF.

\subsubsection{Survey Design and Participants}

A questionnaire was designed to ask the respondents the degree to which each analyzed competence was perceived on both the PF and the anti-PF images. The answers were given using an ordinal Likert scale of equal intervals with the following categories: (1) strongly disagree, (2) disagree, (3) indifferent, (4) agree, (5) strongly agree. A pilot survey was conducted to ensure the understanding of the questions. This pilot survey was answered during personal interviews with 5 people involved in project management tasks.

A total of 23 participants (11 men and 12 women) between 23 and 50 years old $(\mathrm{M}=32.10, \mathrm{SD}=8.63)$ were selected from among members of AEIPRO (the Spanish IPMA partner) and graduates of a Project Management Master's Degree. The sampling procedure 
was the same used in the first phase. We systematically sampled a list of candidates ordered by age. All participants provided informed consent to participate.

\subsubsection{Data Collection and Analysis}

Data collection was carried out through personal meetings with the participants. In these personal meetings, participants were given a brief explanation of the procedure and received information about the way to answer the questionnaire. They were asked to respond quickly, guided by their first impression.

In one part of the survey, the PF was shown to the participants who answered the questions corresponding to each competence according to the visual perception of the face. In the other part, which was performed in a different session, the anti-PF was shown to the respondents, who answered the same questions about this face. The order in which both parts of the survey were performed was randomized for each participant.

Mean and standard deviation of the scores for each competence were calculated for the answers given to the PF and the anti-PF and dependent-samples t-tests $(\alpha=0.05)$ were conducted to compare the means.

\section{Results}

The PF and the anti-PF obtained in the first phase of this study are shown in Figure 3. We performed a test on the noise data of the CIs to check the pixels of the stimuli that significantly influenced the judgment. A Gaussian filter (radius $=5$ pixels) and a mask hiding the background of the image were applied on CIs noise patterns. We used the rcicr $\mathrm{R}$ package to Z-transform the luminance of the pixels of the CIs noise [51] and to perform a cluster test (threshold $z$-score $=1.5$ ) [63]. In this way, the pixels that significantly influence the stimuli selected by the respondents were identified and visualized in a z-map (Figure 4). Green clusters correspond to zones of the $\mathrm{CI}$ that directly correlate with the perception of a face with the competences of a PM, while the red and white zones do it inversely.

The complete set of scores obtained in the second phase of this work is available in Appendix A (Table A1) and the means, the standard deviations, and the confidence intervals of the scores for each competence given to the PF and the anti-PF are presented in Table 2. The $t$-values of the dependent-samples $t$-tests $(\alpha=0.05)$ are shown in the last column of the same table. There were significant differences in all the competences between the faces $(p<0.05)$. These results are summarized in Figure 5.

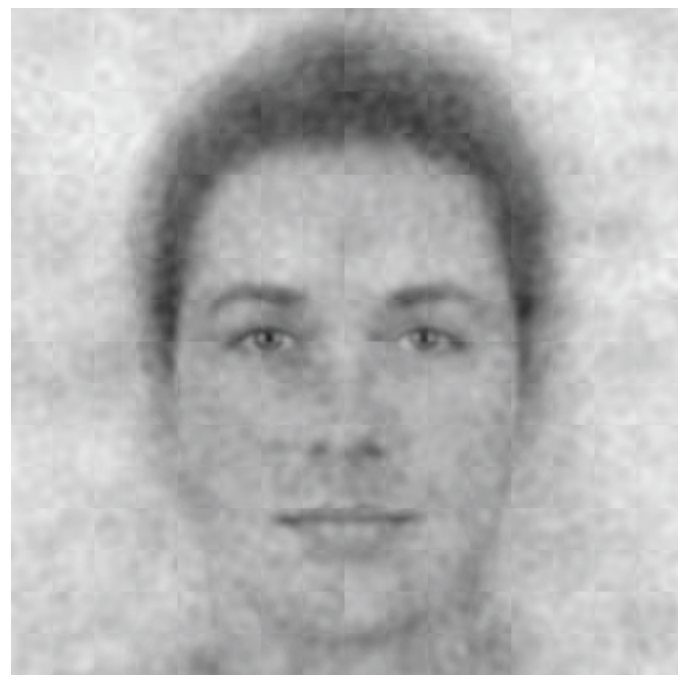

(a)

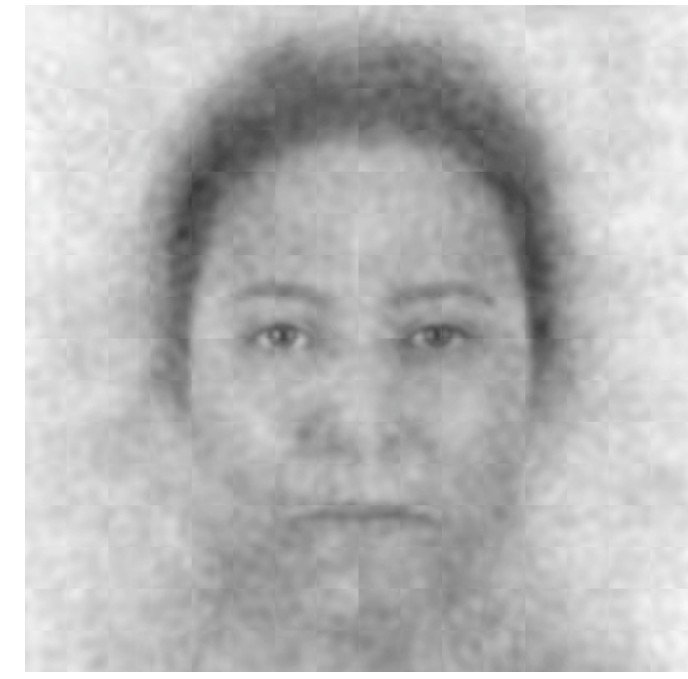

(b)

Figure 3. Results of the NBRC task: (a) project manager prototypical face; (b) project manager anti-prototypical face. 

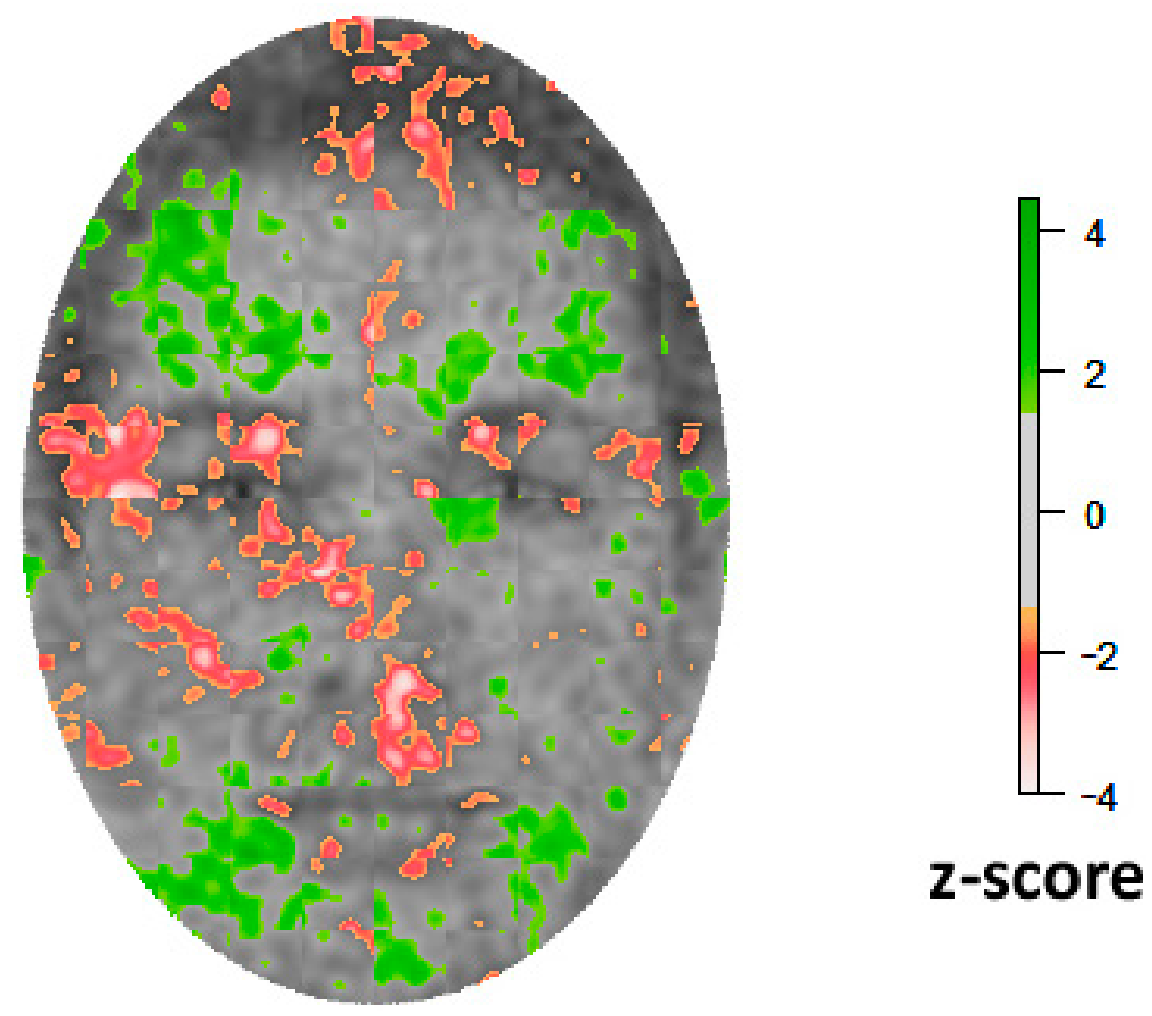

Figure 4. Clusters of pixels that significantly influence the stimuli classification. Green zones correlated positively with PF classification. Red and white zones correlated negatively.

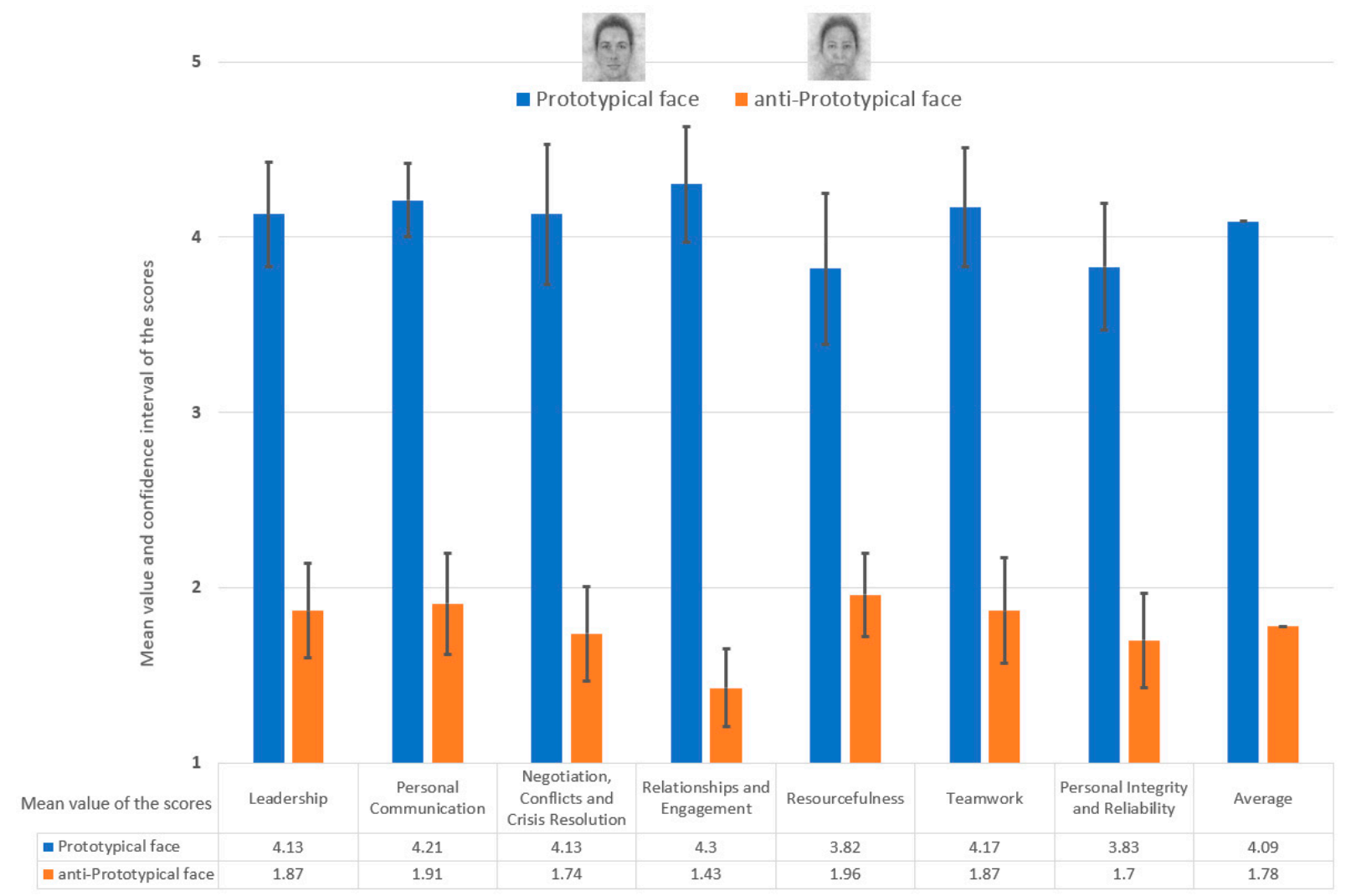

Figure 5. Mean value and confidence interval of the scores of the competences for the project manager prototypical face and the project manager anti-prototypical face. 


\section{Discussion}

The outcomes of the NBRC task performed in this study are shown in Figure 3. These faces are psychologically meaningful images that represent the PF (and the anti-PF) that the participants in the task used to match the perception of a prototypical PM. Therefore, the PF shows the features of the faces that drive the judgment and can be considered an estimation of the participants' mental representation of a face that fits a PM. In the same way, the anti-PF image shows the features of the face that do not drive the sensation of a PM's face [51]. A visual inspection of the faces in Figure 3 shows significant differences in some facial features (the nose, the eyebrows, and the mouth) and even the contour of the jaw.

As expected, the mean of the scores given by the participants in the survey performed in the second phase of this study for the seven competences analyzed have been higher for the PF than for the anti-PF. In all cases, the differences are statistically significant.

The PF shows a very high average assessment $(\mathrm{M}=4.08)$ considering all the competences studied (corresponding to "agree" in the questionnaire). The most elicited competence is Relationships and Engagement $(\mathrm{M}=4.3 ; \mathrm{SD}=0.76)$, followed by Communication $(\mathrm{M}=4.21 ; \mathrm{SD}=0.42)$, Teamwork $(\mathrm{M}=4.17 ; \mathrm{SD}=0.77)$, Leadership $(\mathrm{M}=4.13 ; \mathrm{SD}=0.69)$, and Negotiation, Conflicts, and Crisis Resolution $(\mathrm{M}=4.13 ; \mathrm{SD}=0.91)$. While Relationships and Engagement is the best-perceived competence in the $\mathrm{PF}$, is the less elicited by the anti-PF $(\mathrm{M}=1.43 ; \mathrm{SD}=0.51)$. Resourcefulness is competence with higher mean score in the anti-PF, but it does not exceed the score for "disagree" $(\mathrm{M}=1.96$; $\mathrm{SD}=0.56)$.

As aforementioned, personality traits, capacities, and competences are inferred by our cognitive system from faces [10]. This unconscious process plays a central role in our everyday decisions $[15,16]$ and greatly influences how we choose our partners $[16,17,21,22]$. But for the observer to be able to make complex judgments about a person or infer complex competences, the mere appearance of a face is not enough. For this to happen, we need a mental prototype that summarizes the appearance of a person who possesses these characteristics. From the results of this work, it can be stated that people have clearly defined prototypes of facial features that convey the sensation of being a competent project manager, and this finding has important implications in the project management field.

As more organizations adopt project management approaches and the demand for project managers grows, interest in project manager competence and standards for developing and assessing project management competence increases. Project management standards are widely used throughout the world in training, professional certification programs, and corporate project management methodologies, assuming there is a positive relationship between the standards and effective performance in workplaces. The impact of personal competences of PMs on project success has been widely studied [29,64]; since the key to project success is to recruit the right PM, several studies focus on recruiting an adequate PM whose skills fit the challenges of the project based on competences [27]. Müller and Turner [28] argue that emotional competences always make a significant contribution to project success. The personal competences are difficult to assess due to their intrinsic subjectivity, and, according to some authors [36], most of the PMs selection procedures are based on a subjective assessment of the candidates. As we have found, there are prototypical facial features that elicit to the observers the competences of PMs, and, therefore, the perceptual assessment processes implied in selection procedures could be unconsciously conditioned by the appearance of the candidates.

Obviously, there is no evidence to suggest that the owner of a face that looks like a good PM is actually a good PM. Therefore, the appearance of the candidates for a PM position may affect the final decision, introducing an undesired bias in the process. Some social impact benefits of sustainable projects come from good employment practices, such as adequate recruiting processes $[65,66]$. According to our findings, the appearance of candidates may detract from the objectivity of the recruiting process, thus reducing the social impact benefits of the projects. 
But the implications may be not limited to the selection procedures. Previous studies have shown that, in similar fields, appearance can predict company profits [24] and that people with competent and dominant-looking faces receive larger salaries and are hired by more important companies independently of their performance [25]. The same may occur in project management teams, appearance-based judgments may negatively influence labor practices related to diversity and remuneration, benefits, and career opportunities, which are key features of socially sustainable projects [66].

However, more research is needed to determine the real role and implications of the prototypical appearance on the selection procedures and the career of PMs. Now we have an image of the facial features of the prototypical face of a PM. Our future work will intend to measure the real effects of the appearance of the candidates on the selection procedures outcomes.

On the other hand, we will study if there are differences in the perception of PM competences depending on the gender of the observer and the gender of the PM. The data collected in this study suggest that such differences exist. The study of the gender gap in the project management field has gradually broadened to include different perspectives $[67,68]$. Historically, project management can be considered a male-dominated discipline. Gender bias for job access is a particular problem for a male-dominated profession like project management. Even the consideration of gender is an issue in decisions related to perceived competence [69]. Sustainable projects can provide social impact benefits by implementing gender policies in their labor practices [70]. In this sense, we propose a new line for future research that analyzes differences in the perception of the appearance of faces from a gender approach.

\section{Conclusions}

We have obtained an image of the prototypical face of a project manager using an NBRC task. The image shows the features of the faces that drive the perception of a good project manager, therefore, it can be considered an estimation of the participants' mental representation of a face that fits a project manager.

An independent sample of participants measured to what extent the competences studied in this work were elicited by the obtained prototypical face. The face shows a very high average assessment for all the competences studied in this work.

It can be stated that people have clearly defined prototypes of facial features that convey the sensation of being a competent project manager, and this finding has important implications in the procedures of selection of project managers.

Author Contributions: Conceptualization, J.-A.D.-M. and R.P.-B.; methodology, J.A.-M. and J.-A.D.M.; validation, J.-A.D.-M. and R.P.-B.; investigation, J.-A.D.-M. and R.P.-B.; writing—original draft preparation, J.-A.D.-M. and R.P.-B.; writing-review and editing, J.A.-M. All authors have read and agreed to the published version of the manuscript.

Funding: This research received no external funding.

Institutional Review Board Statement: The study was conducted according to the guidelines of the Declaration of Helsinki, and approved by the Ethics Committee of the Universitat Politècnica de València (protocol code P15_10_01_20; date of approval 01/14/2020).

Informed Consent Statement: Informed consent was obtained from all subjects involved in the study.

Data Availability Statement: The data presented in this study are available in Appendix A.

Acknowledgments: We thank J. Conrad Jackson, N. Hester, and K. Gray, authors of the image used as the base face in this study with their kind permission.

Conflicts of Interest: The authors declare no conflict of interest. 


\section{Appendix A}

Table A1. Scores by participant and competence in the evaluation of the competences elicited by the prototypical face.

\begin{tabular}{ccccccccccccccc}
\hline & & \multicolumn{3}{c}{ PF } & \multicolumn{7}{c}{ Anti-PF } \\
\hline Competence & C1 & C2 & C3 & C4 & C5 & C6 & C7 & C1 & C2 & C3 & C4 & C5 & C6 & C7 \\
\hline P1 & 5 & 4 & 4 & 5 & 4 & 4 & 4 & 1 & 1 & 1 & 1 & 2 & 1 & 1 \\
P2 & 3 & 4 & 3 & 5 & 5 & 3 & 4 & 1 & 2 & 1 & 2 & 2 & 2 & 1 \\
P3 & 4 & 4 & 4 & 4 & 5 & 5 & 4 & 2 & 2 & 2 & 2 & 2 & 1 & 2 \\
P4 & 4 & 4 & 1 & 4 & 1 & 2 & 4 & 1 & 1 & 1 & 1 & 1 & 1 & 1 \\
P5 & 5 & 5 & 5 & 5 & 4 & 5 & 5 & 2 & 1 & 1 & 1 & 1 & 1 & 2 \\
P6 & 5 & 5 & 5 & 5 & 5 & 4 & 5 & 1 & 1 & 2 & 1 & 3 & 2 & 1 \\
P7 & 5 & 4 & 4 & 4 & 4 & 4 & 4 & 2 & 2 & 3 & 2 & 1 & 3 & 2 \\
P8 & 4 & 4 & 3 & 5 & 4 & 5 & 4 & 2 & 2 & 2 & 1 & 2 & 2 & 2 \\
P9 & 5 & 5 & 5 & 5 & 5 & 5 & 5 & 2 & 2 & 2 & 1 & 3 & 3 & 2 \\
P10 & 4 & 4 & 5 & 5 & 4 & 5 & 4 & 2 & 1 & 1 & 1 & 2 & 1 & 2 \\
P11 & 4 & 4 & 4 & 3 & 2 & 4 & 4 & 2 & 3 & 3 & 2 & 2 & 3 & 2 \\
P12 & 4 & 4 & 4 & 4 & 3 & 4 & 4 & 2 & 2 & 2 & 2 & 2 & 2 & 2 \\
P13 & 4 & 4 & 5 & 5 & 4 & 4 & 4 & 3 & 2 & 2 & 2 & 2 & 3 & 3 \\
P14 & 4 & 4 & 5 & 5 & 4 & 5 & 4 & 2 & 2 & 2 & 2 & 2 & 2 & 2 \\
P15 & 4 & 4 & 4 & 4 & 3 & 4 & 4 & 3 & 2 & 2 & 2 & 3 & 2 & 3 \\
P16 & 4 & 4 & 5 & 4 & 4 & 5 & 4 & 1 & 2 & 1 & 1 & 2 & 1 & 1 \\
P17 & 4 & 5 & 4 & 4 & 4 & 4 & 5 & 2 & 3 & 2 & 2 & 2 & 2 & 2 \\
P18 & 4 & 4 & 5 & 2 & 4 & 3 & 4 & 2 & 3 & 2 & 1 & 2 & 2 & 2 \\
P19 & 3 & 4 & 4 & 4 & 3 & 4 & 4 & 2 & 2 & 2 & 2 & 2 & 2 & 2 \\
P20 & 3 & 4 & 4 & 4 & 4 & 4 & 4 & 2 & 3 & 2 & 1 & 2 & 2 & 2 \\
P21 & 5 & 5 & 4 & 5 & 5 & 5 & 5 & 1 & 1 & 1 & 1 & 1 & 1 & 1 \\
P22 & 5 & 4 & 4 & 4 & 4 & 4 & 4 & 2 & 2 & 1 & 1 & 2 & 2 & 2 \\
P23 & 3 & 4 & 4 & 4 & 3 & 4 & 4 & 3 & 2 & 2 & 1 & 2 & 2 & 3 \\
\hline
\end{tabular}

C1: Leadership; C2: Personal Communication; C3: Negotiation, Conflicts and Crisis Resolution; C4: Relationships and Engagement; C5: Resourcefulness; C6: Teamwork; C7: Personal Integrity and Reliability.

Table 2. Mean value, confidence interval and standard deviation of the scores of the competences for the PF and the anti-PF.

\begin{tabular}{cccccc}
\hline Competence & PF & \multicolumn{2}{c}{ Anti-PF } \\
\hline & $\mathbf{M} \pm \mathbf{C I}$ & SD & M & SD & $t$-Value \\
\hline Leadership & $4.13 \pm 0.30$ & 0.69 & $1.87 \pm 0.27$ & 0.63 \\
Personal Communication & $4.21 \pm 0.21$ & 0.42 & $1.91 \pm 0.29$ & 0.67 & 10.29 \\
Negotiation, Conflicts and Crisis Resolution & $4.13 \pm 0.40$ & 0.92 & $1.74 \pm 0.27$ & 0.62 & 11.10 \\
Relationships and Engagement & $4.30 \pm 0.33$ & 0.76 & $1.43 \pm 0.22$ & 0.51 \\
Resourcefulness & $3.82 \pm 0.43$ & 0.98 & $1.96 \pm 0.24$ & 0.56 & 0.69 \\
Teamwork & $4.17 \pm 0.34$ & 0.78 & $1.87 \pm 0.30$ & 10.00 \\
Personal Integrity and Reliability & $3.83 \pm 0.36$ & 0.83 & $1.70 \pm 0.27$ & 0.63 \\
\hline Average & 4.09 & & & \\
\hline
\end{tabular}

$p<0.05 . \mathrm{M}=$ Mean. $\mathrm{CI}=$ Confidence interval. $\mathrm{SD}=$ Standard deviation.

\section{References}

1. Kanwisher, N.; McDermott, J.; Chun, M.M. The Fusiform Face Area: A module in human extrastriate cortex specialized for the perception of faces. J. Neurosci. 1997, 17, 4302-4311. [CrossRef] [PubMed]

2. Schobert, A.-K.; Corradi-Dell'Acqua, C.; Frühholz, S.; van der Zwaag, W.; Vuilleumier, P. Functional organization of face processing in the human superior temporal sulcus: A 7T high-resolution fMRI study. Soc. Cogn. Affect. Neurosci. $2018,13$. [CrossRef] [PubMed]

3. Damasio, A.R. Prosopagnosia. Trends Neurosci. 1985, 8, 132-135. [CrossRef]

4. Bruce, V.; Young, A. Understanding face recognition. Br. J. Psychol. 1986, 77, 305-327. [CrossRef]

5. Bruce, V.; Young, A. Face Perception; Psychology Press: New York, NY, USA, 2012. 
6. Diego-Mas, J.-A.; Fuentes-Hurtado, F.; Naranjo, V.; Alcañiz, M. The Influence of Each Facial Feature on How We Perceive and Interpret Human Faces. Iperception 2020, 11. [CrossRef]

7. Fuentes-Hurtado, F.; Diego-Mas, J.A.; Naranjo, V.; Alcañiz, M. Automatic classification of human facial features based on their appearance. PLoS ONE 2019, 14, e0211314. [CrossRef] [PubMed]

8. Blick, S. Set in Stone: The Face in Medieval Sculpture. Sixt. Century J. 2008, 39, 924. [CrossRef]

9. Todorov, A.; Olivola, C.Y.; Dotsch, R.; Mende-Siedlecki, P. Social Attributions from Faces: Determinants, Consequences, Accuracy, and Functional Significance. Annu. Rev. Psychol. 2015, 66, 519-545. [CrossRef]

10. Brinkman, L.; Todorov, A.; Dotsch, R. Visualising mental representations: A primer on noise-based reverse correlation in social psychology. Eur. Rev. Soc. Psychol. 2017, 28, 333-361. [CrossRef]

11. Dotsch, R.; Wigboldus, D.H.J.; van Knippenberg, A. Biased allocation of faces to social categories. J. Pers. Soc. Psychol. 2011, 100, 999-1014. [CrossRef]

12. Freeman, J.B.; Ambady, N. The dynamic interactive model of person construal: Coordinating sensory and social processes. In Dual-Process Theories of the Social Mind; Sherman, J.W., Gawronski, B., Trope, Y., Eds.; Guilford Press: New York, NY, USA, 2014; ISBN 9781462514397.

13. Kahneman, D. A Perspective on Judgment and Choice: Mapping Bounded Rationality. Am. Psychol. 2003, 58, 697-720. [CrossRef] [PubMed]

14. Todorov, A.; Said, C.P.; Engell, A.D.; Oosterhof, N.N. Understanding evaluation of faces on social dimensions. Trends Cogn. Sci. 2008, 12, 455-460. [CrossRef] [PubMed]

15. Todorov, A. Evaluating Faces on Social Dimensions. In Social Neuroscience: Toward Understanding the Underpinnings of the Social Mind; Oxford University Press: Oxford, UK, 2011; ISBN 9780199893324.

16. Little, A.C.; Burriss, R.P.; Jones, B.C.; Roberts, S.C. Facial appearance affects voting decisions. Evol. Hum. Behav. 2007, 28 , 18-27. [CrossRef]

17. Langlois, J.H.; Kalakanis, L.; Rubenstein, A.J.; Larson, A.; Hallam, M.; Smoot, M. Maxims or myths of beauty? A meta-analytic and theoretical review. Psychol. Bull. 2000, 126, 390-423. [CrossRef]

18. Bovet, J.; Barthes, J.; Durand, V.; Raymond, M.; Alvergne, A. Men's Preference for Women's Facial Features: Testing Homogamy and the Paternity Uncertainty Hypothesis. PLoS ONE 2012, 7, e0049791. [CrossRef] [PubMed]

19. Dixson, B.J.W.; Sulikowski, D.; Gouda-Vossos, A.; Rantala, M.J.; Brooks, R.C. The masculinity paradox: Facial masculinity and beardedness interact to determine women's ratings of men's facial attractiveness. J. Evol. Biol. 2016, 29, 2311-2320. [CrossRef]

20. Keating, C.F.; Doyle, J. The faces of desirable mates and dates contain mixed social status cues. J. Exp. Soc. Psychol. 2002, 38, 414-424. [CrossRef]

21. Todorov, A.; Mandisodza, A.N.; Goren, A.; Hall, C.C. Psychology: Inferences of competence from faces predict election outcomes. Science 2005, 308, 1623-1626. [CrossRef]

22. Eberhardt, J.L.; Davies, P.G.; Purdie-Vaughns, V.J.; Johnson, S.L. Looking deathworthy perceived stereotypicality of black defendants predicts capital-sentencing outcomes. Psychol. Sci. 2006, 17, 383-386. [CrossRef]

23. Jack, R.E.; Schyns, P.G. The Human Face as a Dynamic Tool for Social Communication. Curr. Biol. 2015, 25, R621-R634. [CrossRef]

24. Rule, N.O.; Ambady, N. The face of success: Inferences from Chief Executive Officers' Appearance Predict Company Profits. Psychol. Sci. 2008, 19, 109-111. [CrossRef] [PubMed]

25. Graham, J.R.; Harvey, C.R.; Puria, M. A corporate beauty contest. Manage. Sci. 2017, 63, 3044-3056. [CrossRef]

26. Livingston, R.W.; Pearce, N.A. The Teddy-Bear Effect. Psychol. Sci. 2009, 20, 1229-1236. [CrossRef] [PubMed]

27. Liikamaa, K. Developing a Project Manager's Competencies: A Collective View of the Most Important Competencies. Procedia Manuf. 2015, 3, 681-687. [CrossRef]

28. Müller, R.; Turner, J.R. Matching the project manager's leadership style to project type. Int. J. Proj. Manag. 2007, 25, 21-32. [CrossRef]

29. El-Sabaa, S. The skills and career path of an effective project manager. Int. J. Proj. Manag. 2001, 19, 1-7. [CrossRef]

30. Crawford, L. Senior management perceptions of project management competence. Int. J. Proj. Manag. 2005, 23, 7-16. [CrossRef]

31. World Economic Forum. The Future of Jobs Report; World Economic Forum: Colony, Switzerland, 2020.

32. Pereira, L.; Santos, R.; Sempiterno, M.; Costa, R.L.D.; Dias, Á.; António, N. Pereira Problem Solving: Business Research Methodology to Explore Open Innovation. J. Open Innov. Technol. Mark. Complex. 2021, 7, 84. [CrossRef]

33. Institute, P.M. Project Manager Competency Development Framework, 3rd ed.; Project Management Institute: Pennsylvania, PA, USA, 2017.

34. Vukomanović, M.; Young, M.; Huynink, S. IPMA ICB 4.0-A global standard for project, programme and portfolio management competences. Int. J. Proj. Manag. 2016, 34, 1703-1705. [CrossRef]

35. Crawford, L. Profiling the Competent Project Manager. In Proceedings of the Project Management Research at the Turn of the Millenium: Proceedings of PMI Research Conference; Sylva, N.C., Ed.; Project Management Institute: Paris, France, 2000; pp. 3-15.

36. Ogunlana, S.; Siddiqui, Z.; Yisa, S.; Olomolaiye, P. Factors and procedures used in matching project managers to construction projects in Bangkok. Int. J. Proj. Manag. 2002, 20, 385-400. [CrossRef]

37. International Project Management Association (IPMA). IPMA Individual Competence Baseline; v 4.0.; International Project Management Association (IPMA): Nijkerk, The Netherlands, 2015; ISBN 9789492338013.

38. Peters, T.; Waterman, R. In Search of Excellence: Lessons from America's Best-Run Corporations; Harper \& Row: New York, NY, USA, 1982. [CrossRef] 
39. Rosenau, M.D.; Githens, G.D. Successful Project Management: A Step-by-Step Approach with Practical Examples; John Wiley \& Sons: San Francisco, CA, USA, 2011; ISBN 1118276906.

40. Müller, R.; Turner, R. Leadership competency profiles of successful project managers. Int. J. Proj. Manag. 2010, 28, 437-448. [CrossRef]

41. Brill, J.M.; Bishop, M.J.; Walker, A.E. The competencies and characteristics required of an effective project manager: A Web-based Delphi study. Educ. Technol. Res. Dev. 2006, 54, 115-140. [CrossRef]

42. Kadefors, A. Trust in project relationships-Inside the black box. Int. J. Proj. Manag. 2004, 22, 175-182. [CrossRef]

43. Verma, V. Human Resource Skills for the Project Manager-The Human Aspects of Project Management; Project Management Institute: Pennsylvania, PA, USA, 1996; Volume 2.

44. Kliem, R.L.; Ludin, I.S. The People Side of Project Management; Gower Publishing Company, Limited: Aldershot, UK, 1992; ISBN 0566073633.

45. Wysocki, R.K. Effective Project Management: Traditional, Agile, Extreme; John Wiley \& Sons: San Francisco, CA, USA, 2011; ISBN 9788578110796.

46. Dolfi, J.; Andrews, E.J. The subliminal characteristics of project managers: An exploratory study of optimism overcoming challenge in the project management work environment. Int. J. Proj. Manag. 2007, 25, 674-682. [CrossRef]

47. Bushuyeva, N.; Bushuiev, D.; Busuieva, V.; Achkasov, I. IT Projects Management Driving by Competence. In Proceedings of the 2018 IEEE 13th International Scientific and Technical Conference on Computer Sciences and Information Technologies (CSIT), Lviv, Ukraine, 11-14 September 2018; Volume 2, pp. 226-229. [CrossRef]

48. Edmondson, A.; Bohmer, R.; Pisano, G. Harvard Business Review on managing projects. Speeding up Team Learn. October 2021. Available online: https:/ /hbr.org/2001/10/speeding-up-team-learning (accessed on 29 April 2021).

49. Henderson, L.S.; Stackman, R.W.; Lindekilde, R. Why cultural intelligence matters on global project teams. Int. J. Proj. Manag. 2018, 36, 954-967. [CrossRef]

50. Tanaka, J.W.; Farah, M.J. Parts and wholes in face recognition. Q. J. Exp. Psychol. 1993, 46, 225-245. [CrossRef] [PubMed]

51. Todorov, A.; Dotsch, R.; Wigboldus, D.H.J.; Said, C.P. Data-driven methods for modeling social perception. Soc. Personal. Psychol. Compass 2011, 5, 775-791. [CrossRef]

52. Dotsch, R.; Todorov, A. Reverse Correlating Social Face Perception. Soc. Psychol. Personal. Sci. 2012, 3, 562-571. [CrossRef]

53. Dai, H.; Micheyl, C. Psychophysical reverse correlation with multiple response alternatives. J. Exp. Psychol. Hum. Percept. Perform. 2010, 36, 976-993. [CrossRef] [PubMed]

54. Mangini, M.C.; Biederman, I. Making the ineffable explicit: Estimating the information employed for face classifications. Cogn. Sci. 2004, 28, 209-226. [CrossRef]

55. Jack, R.E.; Caldara, R.; Schyns, P.G. Internal representations reveal cultural diversity in expectations of facial expressions of emotion. J. Exp. Psychol. Gen. 2012, 141, 19-25. [CrossRef]

56. Dotsch, R.; Wigboldus, D.H.J.; Langner, O.; van Knippenberg, A. Ethnic Out-Group Faces Are Biased in the Prejudiced Mind. Psychol. Sci. 2008, 19, 978-980. [CrossRef]

57. Kunst, J.R.; Dovidio, J.F.; Dotsch, R. White Look-Alikes: Mainstream Culture Adoption Makes Immigrants "Look" Phenotypically White. Personal. Soc. Psychol. Bull. 2018, 44, 265-282. [CrossRef]

58. Jackson, J.C.; Hester, N.; Gray, K. The faces of god in America: Revealing religious diversity across people and politics. PLoS ONE 2018, 13, e0198745. [CrossRef]

59. Hehman, E.; Flake, J.K.; Freeman, J.B. Static and Dynamic Facial Cues Differentially Affect the Consistency of Social Evaluations. Personal. Soc. Psychol. Bull. 2015, 41, 1123-1134. [CrossRef]

60. Imhoff, R.; Woelki, J.; Hanke, S.; Dotsch, R. Warmth and competence in your face! Visual encoding of stereotype content. Front. Psychol. 2013, 4, 386. [CrossRef] [PubMed]

61. van Rijsbergen, N.; Jaworska, K.; Rousselet, G.A.; Schyns, P.G. With age comes representational wisdom in social signals. Curr. Biol. 2014, 24, 2792-2796. [CrossRef] [PubMed]

62. Dotsch, R. rcicr: Reverse-Correlation Image-Classification Toolbox. Available online: https://cran.r-project.org/web/packages/rcicr/ rcicr.pdf (accessed on 19 December 2020).

63. Chauvin, A.; Worsley, K.J.; Schyns, P.G.; Arguin, M.; Gosselin, F. Accurate statistical tests for smooth classification images. J. Vis. 2005, 9. [CrossRef] [PubMed]

64. Yang, L.R.; Huang, C.F.; Wu, K.S. The association among project manager's leadership style, teamwork and project success. Int. J. Proj. Manag. 2011, 29, 258-267. [CrossRef]

65. Silvius, A.J.G.; Schipper, R.P.J. Sustainability in project management: A literature review and impact analysis. Soc. Bus. 2014, 4, 63-96. [CrossRef]

66. Martens, M.L.; Carvalho, M.M. Key factors of sustainability in project management context: A survey exploring the project managers' perspective. Int. J. Proj. Manag. 2017, 35, 1084-1102. [CrossRef]

67. Pinto, J.K.; Patanakul, P.; Pinto, M.B. “The aura of capability": Gender bias in selection for a project manager job. Int. J. Proj. Manag. 2017, 35, 420-431. [CrossRef]

68. Bosak, J.; Sczesny, S. Gender Bias in Leader Selection? Evidence from a Hiring Simulation Study. Sex Roles 2011, 65, $234-242$. [CrossRef] 
69. Heilman, M.E.; Block, C.J.; Martell, R.F. Sex stereotypes: Do they influence perceptions of managers? J. Soc. Behav. Pers. 1995, 10, 237-252.

70. Pereira, L.; Teixeira, C.; Salgado, A. Pereira diamond: Projects' economic and social impacts. In Proceedings of the 2017 International Conference on Engineering, Technology and Innovation (ICE/ITMC), Madeira, Portugal, 27-29 June 2017; IEEE: New York, NY, USA, 2017; pp. 6-14. 